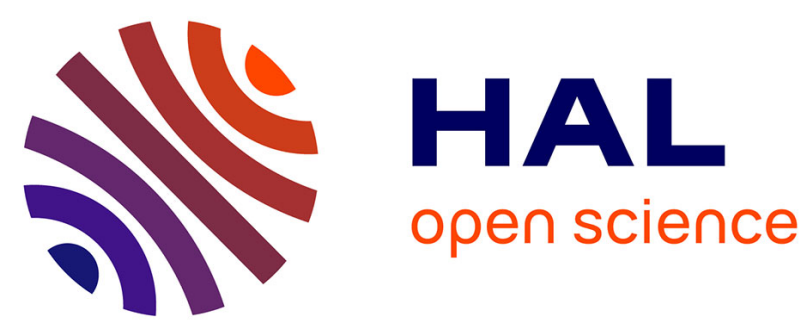

\title{
Maintenance of Facilities and Aircrafts: A Comparison of IT-Driven Solutions
}

\author{
Karoliina Parhiala, Mehmet Yalcinkaya, Vishal Singh
}

\section{To cite this version:}

Karoliina Parhiala, Mehmet Yalcinkaya, Vishal Singh. Maintenance of Facilities and Aircrafts: A Comparison of IT-Driven Solutions. 11th IFIP International Conference on Product Lifecycle Management (PLM), Jul 2014, Yokohama, Japan. pp.11-20, 10.1007/978-3-662-45937-9_2 . hal-01386471

\section{HAL Id: hal-01386471 \\ https://hal.inria.fr/hal-01386471}

Submitted on 24 Oct 2016

HAL is a multi-disciplinary open access archive for the deposit and dissemination of scientific research documents, whether they are published or not. The documents may come from teaching and research institutions in France or abroad, or from public or private research centers.
L'archive ouverte pluridisciplinaire HAL, est destinée au dépôt et à la diffusion de documents scientifiques de niveau recherche, publiés ou non, émanant des établissements d'enseignement et de recherche français ou étrangers, des laboratoires publics ou privés. 


\title{
MAINTENANCE OF FACILITIES AND AIRCRAFTS: A COMPARISON OF IT-DRIVEN SOLUTIONS
}

\author{
Karoliina Parhiala ${ }^{1}$, Mehmet Yalcinkaya ${ }^{2}$ and Vishal Singh ${ }^{3}$ \\ ${ }^{1}$ Aalto Design Factory, Aalto University, Finland \\ ${ }^{2,3}$ Department of Civil and Structural Engineering, Aalto University, Finland \\ \{karoliina.parhiala, mehmet.yalcinkaya, vishal.singh\}@aalto.fi
}

\begin{abstract}
Building Information Modeling (BIM) can significantly impact both new as well as existing architecture/engineering/construction (AEC) projects. It can provide a virtually simulated and large integrated database that can be leveraged not only in design and engineering, but also in planning and management operations, and facilities maintenance. Although most of the BIM tools are now mature enough to use in various phases of project lifecycle, they have been primitive and under-developed for many years. The concepts underpinning BIM have been around since the 1960s through various manufacturing industries such as automotive, ship building or aerospace. In the aerospace industry, especially in aircraft design and manufacturing, the concept similar to BIM is a Digital Mock-Up (DMU). It is both a tool and a product of engineering. As in BIM, aircraft's DMU is also a comprehensive digital product representation that is used to simulate the use, behavior and performance of a finished aircraft. While BIM and DMU are used for different industries and products, they do share similarities and differences. This paper briefly describes BIM and DMU technologies and their context, specifically focusing on implementation of these two technologies for operation and maintenance (O\&M).
\end{abstract}

Keywords: Building Information Modeling, BIM, Digital Mockup, DMU, Configured Digital Mockup, cDMU, Maintenance

\section{Introduction}

From the phases of the lifecycle of any type of manufacturing project, the operations and maintenance (O\&M) phase is the longest one and is expected to cover previous costs of its lifecycle phases and to produce profits for its owner. O\&M can be defined as "all actions that have the objective of retaining or restoring an item in or to a state in which it can perform its required function to ensure related business operations are efficient in terms of using the optimum resource as needed, and meeting customer requirements. These actions include the combination of all technical and corresponding administrative, managerial and supervision activities" [1]. O\&M services include different activities with respect to the nature of the related 
industry. The critical aspect to achieve the objectives of O\&M services is information management and application of state-of-art technologies to the related industry.

This paper presents two state-of-art IT-driven approaches towards product lifecycle management (PLM); Building Information Modeling (BIM), specifically developed for architectural/engineering/construction (AEC) and Digital Mock-Up (DMU) applied in mechanical engineering, especially in aviation industry. The paper describes BIM and DMU technologies and presents logical and functional similarities between them in product development and finally focuses on implementation of these two systems for O\&M phase of the associated products’ lifecycle.

\section{IT-Driven Solutions for PLM: DMU and BIM}

\section{a. Digital Mockup (DMU)}

Digital Mock-Up is a terminology used for 3D representation of a product. It is composed of $3 D$ Models, Computer Aided Design (CAD) native files and/or visualization data, and Configuration Metadata. The metadata is Product Structure with parent-child relations and positioning information, and Attributes for lifecycle management. Attributes are all the business and technical information of the product. This means that besides including the data of products' parts, it holds information at least on work sharing, industrial flow, regulations of authorities, change process and configuration management. DMU is more than a CAD file. DMU integrates data from engineering, manufacturing and maintenance, and uses the data to simulate various industrial processes, uses, behavior and performance of the finished product [2].

Barring a few exceptions, e.g. [2], there are limited academic studies on DMU, and nearly all of the knowledge on DMU comes from aviation industry. Most outspoken on using DMU in their product development process has been the aircraft manufacturer Airbus S.A.S [3]. Therefore, the concept of DMU is presented through an example of DMU at Airbus. For Airbus, DMU is the source of all the original product information and the binding reference in all Airbus's operations. But first of all, it was created to service the design and engineering processes. Everybody, inside and outside Airbus, subcontractors and suppliers are expected to work with the same DMU, from the same, shared database and access the latest information possible [4]. DMU at Airbus is presented in figure 1. The DMU can be accessed through several different views. This way, the user can not only access the data that is relevant to his/her work, but the connection of the data still remains within the product structure. [5] Different views are represented in Figure 2.

DMU starts at the design phase from where on, the whole lifecycle of the aircraft can be envisioned [5]. It is used for aircraft representation, assist the communication and decision making throughout whole lifecycle of the aircraft. With the DMU, different kinds of scenarios to visualize and test various design solutions, for example cockpit ergonomics, are created. For aircraft performance and structural analysis, the DMU provides behavior simulations already in the early stages of the development. To reduce physical prototypes to minimum, the DMU is utilized to simulate and 
optimize the work in manufacturing factories, validate the transport concept and plan the final assembly line. [4]

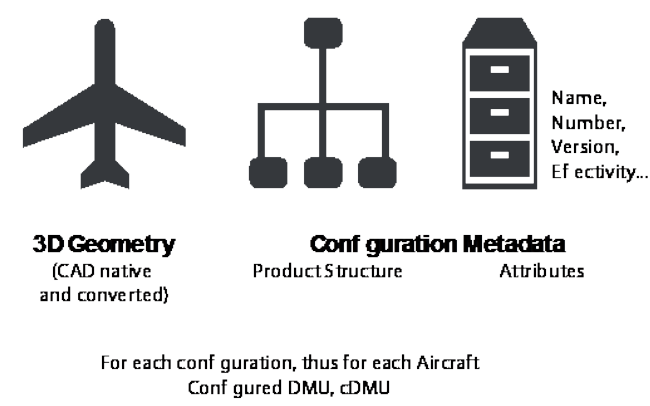

Figure 1. Definition of the Configured Digital Mock-Up at Airbus [4]
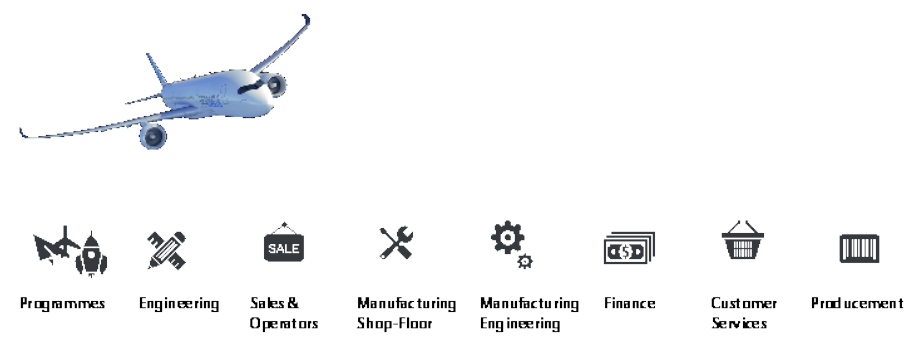

Figure 2. Different disciplines extract their views from the Aircraft [3]

For each product configuration, hence each aircraft configuration, the DMU is called Configured Digital Mock-Up (cDMU). As customers are usually ordering more than one aircraft with the same configuration, the first configured and manufactured aircraft of the order is called Head of Version (HoV). Aircraft manufactured later with the same configuration are copies of the HoV. The cDMU is designed only for $\mathrm{HoV}$, but then copied and linked to all aircrafts with the same configuration. As a result every manufactured aircraft has its own cDMU [4].

\section{b. Building Information Modeling (BIM)}

BIM represents both the technology as well as the process of digital representation of a facility through the use of object-oriented, data-rich, models potentially across the planning, design, construction and operation phases of the facility. In that sense, unlike DMU with its clear meaning, the terminology BIM is interchangeably used to represent the digital model (Building Information Model), the process (Building Information Modelling), and increasingly the approach to managing the technology and the process (Building Information Management). Nonetheless, the BIM model can be viewed, extracted and analyzed by different stakeholders and user groups to manage, simulate and analyze various aspects of the project for improved decision making, operations and maintenance of the facility [6, 7]. 
BIM is also composed of $3 D$ Models, native CAD files and/or visualization data, and Configuration Metadata. The metadata is Product Structure with parent-child relations, and Attributes that are the main identifiers for model management such as object types, ownership and history. BIM also allows additional Attributes to be added, which can include information about the business and technical information of the objects. This means that besides including the geometry and specifications of the objects in the model, it is possible to add information that can be intelligently used for workflow management, procurement and regulations by defining relationships between such attributes. However, unlike DMU such attributes and information on work sharing, industrial flow, regulations of authorities, change process and configuration management are rarely included in current BIM models. Thus, BIM can be configured and modified regarding the project/task requirements with the potential support of external software and hardware.

Similar to DMU, BIM is expected to be the source of all the project information linked through a shared database. It is expected that in an ideal BIM project the different stakeholders such as the designers, client, contractors, subcontractors and suppliers can work with a shared BIM and access the latest information [8]. The use of a shared database in BIM can ensure that the different model views and data can be checked and updated for consistency and conflict resolution [9].The model can be used to demonstrate the entire building lifecycle from conceptual design to demolition (Figure 3) [10]. Thus, materials' quantity takeoff can be extracted, work definitions and sequences can be defined, so the actual construction progress can be simulated in a virtual environment [11].

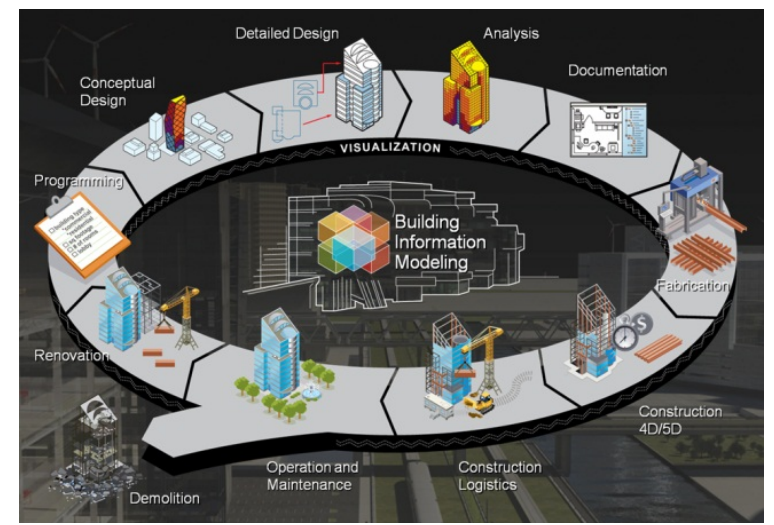

Figure 3. BIM implementation through building lifecycle [10]

However, unlike the Airbus example, where Airbus is clearly the client, manager and coordinator of the DMU through the development stages, the fragmented nature of the construction industry means that the handling of BIM is much more fragmented and complex in the construction sector. The issues of ownership and management of BIM across the different phases remain unclear to most players in the industry. As a result, when compared to the role of Airbus in the development DMU, the following 
generic points can be stated about BIM: (1) BIM discussion has exploded as much in academic research as it has gained the attention of the industry, (2) The role of clients as champions of BIM is critical to the implementation of BIM in practice [12], (3) Unlike, the aerospace industry that has very few, but dominant global players, in the fragmented construction sector the government agencies, regulatory authorities and public clients across different regions have also had to play an important role in binding the use of BIM across different phases of construction projects in the corresponding regions [13].

The discussion on versioning aspect of DMU and cDMU also highlights the following key differences in the context and scope of BIM in construction sector, visà-vis the use of DMU in the aerospace sector: (1) Unlike the aerospace sector, designs in construction projects are typically unique and rarely re-used for multiple instances. This means the concepts of Model Versions in BIM are entirely different to Model Versions in DMU. Instead, versioning in BIM is typically associated with aspects such as levels of detail (LOD), solution alternatives and different stages of model development [8], (2) Since versioning in BIM is more about model coordination within the same project rather than across different instances of the product, instead of the concept of Head of Versions, typically the concepts of Reference Models is used in BIM development. Typically the Reference Model from one discipline is used to coordinate the models of all the other disciplines to ensure version compatibility, and (3) Unlike the aerospace industry where the DMU can be directly used for fabrication, the lack of automation from design to fabrication in construction industry means that the Reference Models typically vary across the different phases of the construction projects, because the as-built facility typically varies from the as-designed model resulting from the changes and inaccuracies in the construction phase. In the design phase, the architecture model is typically the Reference Model, while in the construction phase, the construction model may become the Reference Model. Similarly, it is expected that the as-built model of a facility should become the Reference Model in the maintenance phase. However, the use of as-built models is rare in practice. The lack of automation between design and fabrication also explains why the LOD is an important aspect of BIM models [14].

In summary, both DMU and BIM are identical in their object-oriented approach, but the differences between them result from their context and the products they create, which have their own metadata requirements. In general, the benefits of both IT-solutions in product development are similar, fundamentally derived from the way in which the user groups can contribute to the shared data model, and use the information [3, 10]. The most common benefits of DMU [3, 5] and BIM [11] include:

- Improved coordination in design through visualized object-oriented data which enables improved design management and change control

- Ability to perform simulation and optimization products’ performance

- Ability to perform cost performance analysis and cost impact of any change in design and manufacturing process

- $\quad$ Reduction in manufacturing risks through identification of manufacturability issues, clash detection, schedule and cost simulations, etc in design process.

- Creation of operation and maintenance information database 


\section{Use of models in maintenance of end products}

\section{a. Aircraft Continuing Airworthiness Management}

Aircraft continuing airworthiness is managed by Continuing Airworthiness Management Organization (CAMO). As stated in European Aviation Safety Agency's directives for maintenance organizations [15], "Continuing Airworthiness means all of the processes ensuring that, at any time in its operating life, the aircraft complies with the airworthiness requirements in force and is in a condition for safe operation". CAMO usually is the operator of the aircraft, whether the aircraft is owned or leased. The organization itself is not responsible for the actual maintenance work, but ensures that all needed maintenance and repairs are performed as demanded. Actual maintenance work is done by authority approved maintenance organization [16].

Aircraft maintenance consists of scheduled and unscheduled maintenance. Unscheduled maintenance is corrective maintenance; repairs of defects. Scheduled maintenance aims to prevent decline of the aircrafts airworthiness. Scheduling is based on aircraft's flight hours, flight cycles and overall time in service [17]. To have the ability to execute the maintenance to secure aircraft's airworthiness, a wide set of data on aircraft and its maintenance procedures is needed. This data can be divided to maintenance data, and aircraft configuration and condition data. Maintenance data is the collection of documents to regulate and guide the aircraft maintenance. It includes aviation authority issued requirements, airworthiness directives and technical data provided by OEM. Aircraft configuration and condition data is general identification information on aircraft and components installed on it. It describes the status of airworthiness directives and history of defects, maintenances and modifications. Records of operational data are also part of aircraft's condition information [5]. Regulated by the authorities [18], the OEM provided technical data should be followed, as shown in Table 1 :

Table 1: OEM Technical data to be provided, as per the regulations [18]

\begin{tabular}{|c|c|c|}
\hline $\begin{array}{r}\text { Aircraft } \\
\text { Description }\end{array}$ & Instructions for maintenance & Operation \\
\hline
\end{tabular}




\begin{tabular}{|c|c|c|}
\hline $\begin{array}{l}\text { Aircraft } \\
\text { specifications to that } \\
\text { detailed level that the } \\
\text { maintenance can be } \\
\text { carried out properly }\end{array}$ & $\begin{array}{l}\text { Aircraft servicing information, including } \\
\text { access points, tools and materials } \\
\text { Information for maintenance scheduling for } \\
\text { each part of the aircraft, with frequency and } \\
\text { extent of the maintenance activities }\end{array}$ & $\begin{array}{l}\quad \text { Aircrafts } \\
\text { operation and } \\
\text { control } \\
\text { instructions } \\
\text { with }\end{array}$ \\
\hline $\begin{array}{cr}\text { Descriptions } & \text { and } \\
\text { installations } & \text { of }\end{array}$ & $\begin{array}{l}\text { Airworthiness limitations for damage- } \\
\text { tolerance and fatigue evaluation }\end{array}$ & $\begin{array}{l}\text { procedures in } \\
\text { special }\end{array}$ \\
\hline $\begin{array}{l}\text { aircrafts products and } \\
\text { systems }\end{array}$ & $\begin{array}{l}\text { Dissembling and assembling information of } \\
\text { parts in the aircraft }\end{array}$ & $\begin{array}{l}\text { situations } \\
\text { Instructions }\end{array}$ \\
\hline Structural pictures & Troubleshooting instructions for malfunctions & for ground \\
\hline $\begin{array}{lr}\text { of aircraft } & \text { with } \\
\text { allowable } & \text { working }\end{array}$ & $\begin{array}{l}\text { tructions for special inspection } \\
\text { on-destructive testing }\end{array}$ & $\begin{array}{l}\text { operations, } \\
\text { weighting and }\end{array}$ \\
\hline areas and access plates & Protective treatments after inspections & \\
\hline $\begin{array}{l}\text { Information for } \\
\text { structural fasteners }\end{array}$ & $\begin{array}{l}\text { Electrical wiring interconnection systems } \\
\text { continued airworthiness instructions } \\
\text { List of tools needed }\end{array}$ & \\
\hline
\end{tabular}

\section{DMU in Aircraft Maintenance}

The subject of utilizing the DMU in aircraft maintenance, or any product maintenance, has not been widely addressed. To open a discussion on how the DMU could be deployed in aircraft continuing airworthiness management, a master's thesis was written on the topic. The thesis approaches the topic from user's point of view by conducting interviews with two CAMOs [5]. Results of that thesis are presented here.

Data management to secure aircraft continuing airworthiness is not a new subject; it is a mandatory requirement from aviation authorities. For that reason, sophisticated maintenance management software have been developed and used to manage aircraft configuration and condition, and maintenance data. However, current challenge with those data, especially OEM provided technical data, is that it represents aircrafts in parts. Having a full 3D-model of the whole aircraft would enable the aircraft parts to be examined in their actual context, the aircraft. This visual and spatial information gives better view on the part locations and access to them. Better visualization improves accuracy of maintenance planning and troubleshooting by facilitating the location of components, estimation of man-hours for maintenance tasks, and analysis of potential defects. This would reduce Aircraft on Ground (AOG) -time and make CAMO's operations more efficient.

The key challenges to the deployment of DMU in aircraft airworthiness management are limited resources, competence, time and money. To be able to use DMU as a reliable reference, it should be kept updated so as to correspond to the aircraft configuration and condition at any given point of the aircraft's lifecycle. Another challenge arises from the ownership of the DMU and that the DMU is the core competence and intellectual property of the OEM.

\section{b. Facilities Maintenance}

Facilities maintenance is the continuous process of service provision required to maintain a facility and its environment through its service life. These services 
encompass the entire activities required to assure that a built environment will perform the functions for which the facility was designed and constructed [19]. O\&M phase of a construction project typically includes scheduled, and preventive and emergency maintenance activities of major building systems. Managing the maintenance of facilities can be difficult on the O\&M phase owing to various types of equipment and facilities. Furthermore, it is inconvenient for maintenance staff to maintain those facilities by relying on paper-based documents.

In contrast to the aviation industry, which has the legal obligation to regulate the maintenance of both private and passenger aircrafts and their lifecycle information, such practices and regulations are not common in construction industry. Although many governmental organizations have the responsibility to maintain their buildings, there is no obligation to maintain private buildings. Nonetheless, manuals and strategic maintenance guidelines may be agreed upon through contractual agreement between the owner and contractor. These manuals and guides typically describe the basic information requirements for effective maintenance activities, such as:

- Architectural and structural components of the facility like ceiling surfaces, floor coverings, roofing, and walls.

- $\quad$ Design details, floor plans, spaces and zones, and as-built drawings.

- Environmental considerations, required tools and equipment for safety issues, safety instructions of building systems.

- Equipment lists, descriptions, maintenance and repair guides, operation manuals.

- Preventive maintenance schedules, procedures, logs, troubleshooting guides, removal and replacement instructions of building systems, warranty information.

- Operation instructions of building systems, operation logbooks, start-up and shut-down procedures, emergency operating instructions.

- Descriptions of all systems in buildings, assembly and components diagram, utility connections and cutoff plans.

The listed information requirements are rarely applied to that extent, because of the difficulties to structure and digitally hand them over to a centralized source. As reported by National Institute of Standards and Technology (NIST), "an inordinate amount of time is spent locating and verifying specific facility information from previous activities. Much valuable data associated with the design, construction and operation of a facility is lost during its lifecycle” [20].

\section{BIM in Facilities Maintenance}

BIM can provide a shared resource and information sets about a facility’s structure, functions and technical systems (mechanical, electrical, plumbing, lighting, etc.), including product manufacturers, if available and added to the model. However, construction contracts rarely stipulate providing or using these potential information in BIM models for maintenance activities, and hence, there are very few cases on the actual use of BIM for facilities management. Instead, there are many other technologies that can also exchange the facility data. Building automation systems 
(BAS) or Building Management Systems (BMS) most often handle the operation of building mechanical, electrical, plumbing (MEP) and lightening systems. Integrated Work Management Systems (IWMS) or Computerized Maintenance Management Systems (CMMS) support maintenance activities, work orders, space management, personnel management, etc. However, the exchange and re-usability of the data in these systems and the fragmented nature of AEC industry make the information transfer among project stakeholders challenging, especially through BIM [21].

Therefore, an important point for the success of BIM for facilities maintenance activities is an accurate and structured specification of the BIM data and interoperability of BIM and maintenance software. Construction Operations Building Information Exchange (COBie) has been developed for O\&M data handover [22]. COBie is a rapidly evolving standard to capture information, such as zones, rooms (spaces), equipment and components, tests and certificates, safety and emergency plans, start-up and shut-down procedures, etc. in BIM electronically during design and construction, to provide it to facility managers in a spreadsheet format. It can potentially eliminate the inefficient process of transferring large amounts of paper based documents or electronic data within facility management systems (CMMS, BAS, etc.). To establish the common practice and adoption of BIM-based maintenance management, contractual agreements are needed to stipulate the use and update of COBie data by the project stakeholders. In addition, the COBie standards and templates need further maturity and integration with different BIM applications.

\section{Conclusion}

This paper presents a comparison of BIM and DMU, two different IT-driven solutions applied in AEC and aviation industry respectively. In this paper O\&M phase of the specified industries' products (buildings and aircrafts) are reviewed, and BIM and DMU's value adding functions are discussed. It is proposed that even if the industries and their related domains/products are different, both BIM and DMU apply similar functions for their individual products. However, it is important to understand and analyze the specific circumstances during each domain's lifecycle to figure out the specific needs, strategies to apply related IT-driven solutions. For both solutions, number of issues and potential improvements arise in data management features of related software applications. Potential improvements by means of visualization, data collection/updating and information transfer may ease the BIM/DMU based activities during lifecycle, and make it more efficient.

Future work should include the application of both BIM and DMU for different phases of the lifecycle by highlighting specific workflow issues. Since O\&M phase of both industries include various types of data coming from design and production/construction phases, the specific information requirements for O\&M should be clarified and data/information transfer between these phases may also be a potential area to search. 


\section{References}

[1] European Federation of National Maintenance Societies. URL: http://www.efnms.org/

[2] DOLEZAL, W. R. Success Factors for Digital Mock-ups (DMU) in complex Aerospace Product Development. TU München, Genehmigten Dissertation, Munich, Germany, 2008.

[3] Airbus SAS, Setting new standards with the A350 XWB Digital Mock-Up. http://videos.airbus.com/video/dc6bd25e7f3s.html. Accessed: 11 Jan 2014

[4] Parhiala, K. M Utilising Configured Digital Mock-Up in Aircraft Continuing Airworthiness Management. Aalto University School of Engineering, Master’s Thesis, Finland, 2014.

[5] Garbade, R., and Dolezal, W. R. "DMU@ Airbus_Evolution of the Digital Mock-up (DMU) at Airbus to the Centre of Aircraft Development." The Future of Product Development. Springer Berlin Heidelberg, 2007. 3-12.

[6] Associated General Contractors of America. The Contractor's Guide to BIM, 1st ed. http://www.engr.psu.edu/ae/thesis/portfolios/2008/tjs288/Research/AGC_GuideToBIM.pdf

[7] Mitchell, J et al. Adopting BIM for facilities management: Solutions for managing the Sydney Opera House. CRC-Construction Innovation, Brisbane, Australia (2007).

[8] Gu, N, Singh, V, London, K, Brankovic, L and Taylor, C. BIM : Expectations and a reality check. In: Ren, A, Ma, Z and Lu, X (Eds.), "ICCCBE-XII \& INCITE 2008", Tsinghua University. Tsinghua University Press, 1-6, (2008).

[9] Singh, V. Gu, N. Wang, X. A theoretical framework of a BIM-based multi-disciplinary collaboration platform, Automation in Construction 20(2), (2011) 134-144.

[10] Dispenza, K. The daily life of building information modeling (BIM). URL: http://buildipedia.com/aec-pros/design-news/the-daily-life-of-building-informationmodeling-bim. Accessed: 25 Jan 2014

[11] Khemlani, L. Top criteria for BIM solutions. http://www.aecbytes.com/feature/2007/BIMSurveyReport.html. Accessed: 6 Sep 2013.

[12] Coates, P, Arayici, Y, Koskela, K, Kagioglou, M, Usher, C and O'Reilly, K 2010, The key performance indicators of the BIM implementation process , in: The Int'l Conf. on Computing in Civil and Building Engineering , June 30 - July 2 2010, Nothingham, UK.

[13] Gu, N, Singh, V, Taylor, C, London, K, Ljiljana, B. BIM adoption: expectations across disciplines, (in) Handbook of Research on Building Info. Model'g and Constr. Info.: Concepts and Technologies. Ed Underwood, J. \& Isikdag, U, 501-520, (2010).

[14] Singh, V (2013) Challenges for integrated design and delivery teams in AEC, Proceedings of International Conference on Product Lfecycle Management, Nantes, France 8-10 July.

[15] Maintenance Organisation Approvals - PART-145. Acceptable Means of Compliance and Guidance Material. Luxembourg: European Aviation Safety Agency, 2012, ISBN ISBN 978-92-9210-121-3.

[16] Continuing Airworthiness Requirements - PART-M. Acceptable Means of Compliance and Guidance Material. Luxembourg: Eu. Av. Saf. Ag., 2012, ISBN-13 978-92-9210-123-7

[17] Aubin, B. R. (2004). Aircraft Maintenance: The art and science of keeping aircraft safe, Society of Automotive Engineers, Warrendale, PA. 2004.

[18] Certification Specifications and Acceptable Means of Compliance for Large Aeroplanes. CS-25. Luxembourg: European Aviation Safety Agency, 14.6.2012, 2013.

[19] Whole Building Design Guide, Facilities operation\&maintenance. http://www.wbdg.org/om/om.php Accessed: 19 Jan 2014.

[20] NIST, Cost analysis of inadequate interoperability in the U.S capital and facilities industry, http://fire.nist.gov/bfrlpubs/build04/art022.html. Accessed 23 Dec 2013.

[21] Madritsch, T. May, M. Successful IT implementation in facility management, Facilities 27 $(11 / 12)(2009)$ 429-444.

[22] East, W. bSa Construction Operations Building Information Exchange (COBIE): Means and Methods, The National Institute of Building Sciences, 2012. 